\title{
Pablo Macera Dall'Orso
}

\section{La universidad y las tertulias}

Conocí a Pablo Macera en 1963, siendo estudiante de primer año de Letras en la Universidad San Marcos. Era un profesor brillante, venía a las clases con muchos libros que los mostraba como material didáctico. Él acababa de retornar de sus estudios doctorales en la universidad La Sorbona de París.

Nosotros inauguramos las clases en la Ciudad Universitaria de San Marcos. Se trataba particularmente de la Facultad de Letras donde acudían estudiantes de distintas disciplinas como Historia, Literatura, Geografía, Filosofía, Psicología y Derecho, entre otras. Los profesores eran intelectuales brillantes como Luis Alberto Sánchez, Alberto Tauro del Pino, Emilio Barrantes, José Antonio Russo Delgado, Augusto Tamayo Vargas, Estuardo Núñez, Carlos Araníbar y Raúl Rivera Serna, entre otros. Los cursos que dictaban eran de cultura general, cada uno en sus respectivas especialidades. Una situación particular es que los profesores tenían sus textos universitarios con los cuales estudiábamos las clases a las que no podíamos asistir.

El Dr. Macera en el curso Doctoral que dictaba, llevaba libros de Piere Vilar: Crecimiento y Desarrollo, Economía e Historia, Reflexiones sobre la Guerra Civil Española, los de Marc Bloch: La Historia Rural de Francia, de Eric Hobsbawm: Los Rebeldes Primitivos y Ernest Labrousse: Fluctuaciones Económicas e Historia Social.

A él le gustaba dialogar con los estudiantes y nos invitaba a su casa a participar de las tertulias con sus colegas peruanos y extranjeros. En esas reuniones conocí, entre otros, a don Emilio Choy, a Pierre Vilar, Eric Hobsbawm, Jean Piel, Antonio Melis, Ruggiero Romano y Hugo Pesce. No invitaba a todos los alumnos sino a algunos como Wilson Reátegui, Manuel Burga, Antonio Rengifo, Flores Galindo y Mauro Escobar.

De los intelectuales mencionados líneas arriba, me impresionó particularmente la cultura y el don del habla del maestro Hugo Pesce, quien fue médico de cabecera de José Carlos Mariátegui. Igualmente, la figura de don Emilio Choy, autodidacta y conversador con quien hicimos una larga amistad al punto de que lo considero como uno de mis maestros informales, dándome lecciones fuera de las aulas universitarias.

Las conversaciones eran informales, cada quien planteaba algún problema y sobre él opinaban y discutían los presentes. Algunos éramos más conversadores que otros como fue el caso de don Emilio Choy Ma, con quien rápidamente compartimos ideales políticos. El Dr. Pesce, en una ocasión nos dio un testimonio que nos dejó gratamente impresionados. Pues, nos dijo que él desempeñaba como médico de la Empresa Minera Cerro de Pasco Cooper Corporation en La Oroya. Hacía asistencia médica a los trabajadores que enfermaban, pero, en ocasiones, especialmente los dirigentes, simulaban enfermedad para asistir al consultorio del doctor y recibir

(C) Los autores. Este artículo es publicado por ISHRA, Revista del Instituto Seminario de Historia Rural Andina de la Facultad de Ciencias Sociales de la Universidad Nacional Mayor de San Marcos. Este es un artículo de acceso abierto, distribuido bajo los términos de la licencia Creative Commons Atribución 4.0 Internacional (CC BY 4.0) [https://creativecommons.org/licenses/by/4.0/deed.es] que permite el uso, distribución y reproducción en cualquier medio, siempre que la obra original sea debidamente citada de su fuente original. 
las consignas políticas para las huelgas y luchas que protagonizaba. Las tertulias en la casa del Dr. Macera comenzaban a las 6:30 de la tarde y terminaban a las 9:30 o 10:00 de la noche.

Recuerdo algunas anécdotas. Su primera esposa era tan temperamental como don Pablo y cuando discutían él decía vamos a irnos a la calle a conversar y caminamos una vez desde su casa en José Díaz cerca del Estadio Nacional hasta el final de la Av. Arequipa en el Parque Kennedy. En el transcurso se sosegaba y para retornar a su domicilio él pedía un taxi y yo me iba a mi casa.

Posteriormente, siendo mi Asesor de Tesis Doctoral en Historia, no asistió a la sustentación de la misma, lo cual me perjudicó académicamente distanciándonos amicalmente por un tiempo, más o menos 4 años. En 1975, en un Congreso de Ayacucho hicimos las paces y retomamos nuestra relación amical.

Como nos distanciamos luego del episodio fallido de la sustentación de mi Tesis Doctoral, don Emilio Choy insistía que retomara nuestra amistad, incluso quería que compartiéramos alguna mesa para tomar un café o un lonche en la Ciudad Universitaria, pero el doctor se rehusaba. Este reencuentro solo se concretó en 1975, en la ciudad de Ayacucho, en las conmemoraciones del Sesquicentenario de la Independencia Nacional. La universidad San Cristóbal de Huamanga nos invitó a un conjunto de historiadores para participar en las conferencias y debates conmemorativos, rápidamente los profesores nos dividimos entre los jóvenes profesores de izquierda y los viejos historiadores de derecha. El Dr. Macera quedó en el limbo, de tal suerte que llamó a Alberto Flores Galindo para incorporarse a nuestro grupo, como lo hizo una de esas noches de conversaciones en Ayacucho disculpándose del mal momento que me había hecho pasar al no asistir en su condición de asesor de mi tesis a la defensa programada.

\section{EI Seminario de Historia Rural Andina}

Fue una situación que él creó y que tuvo una vigencia de muchos años. Publicaba de manera frecuente, en tirajes muy cortos y a mimeógrafo, documentos e investigaciones históricas que a la larga sumaron una inmensa cantidad de títulos. Mi participación en el Seminario de Historia Rural Andina no fue constante, sino más bien esporádica, pero debo agradecer al Dr. Macera y a su equipo de trabajo que editaron mimeógrafo la Tesis Bachiller en historia que preparamos conjuntamente con Wilson Reátegui (Figura 1).

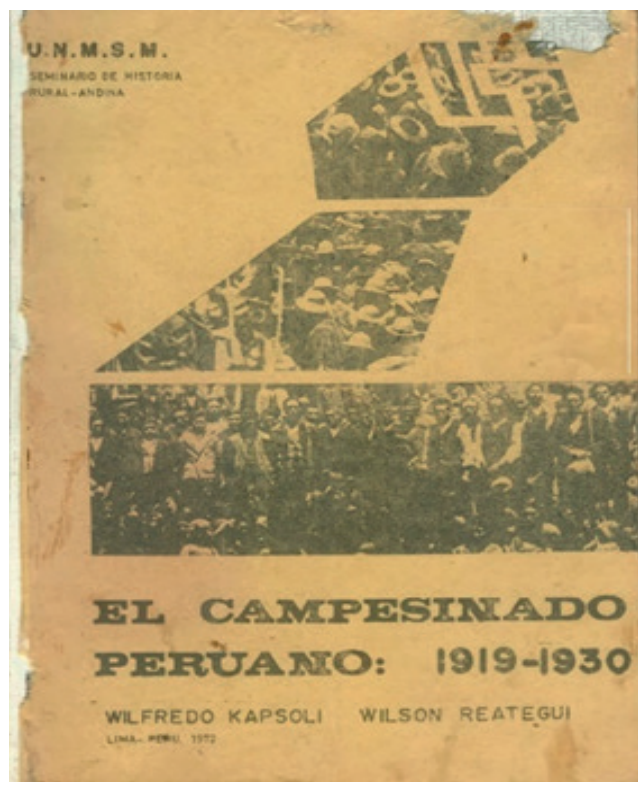

Figura 1. Carátula del libro El campesinado peruano: 1919-1930. Fotografía: Omar Esquivel. 
Antes de egresar de la Universidad, el Dr. Macera nos incorporó a su equipo de trabajo de investigación acerca del Tributo Indígena en el Perú en el siglo XVIII, a su vez, organizamos materiales para publicación de su libro Las Haciendas Coloniales y la Biblioteca de los Jesuitas bajo la responsabilidad de Manuel Burga. El Dr. Macera también hizo las gestiones necesarias para consultar el archivo de Ministerio de Trabajo y Comunidades Indígenas, con cuya documentación elaboré mis tesis, tanto de Bachiller como de Doctor en Letras (Historia), esta última titulada Movimientos Campesinos en Cerro de Pasco.

\section{¿Cómo hay que recordar a Pablo Macera?}

Esa pregunta le hicieron a él cuando participaba en una entrevista televisiva, y él pidió que nadie lo recordara, que cada quien pensara en su propia vida y en su entorno cercano, pero creo que eso fue un arranque de su estado anímico inestable por los problemas afectivos que había tenido. Pero, hablando con seriedad, hay que releer sus trabajos, su entusiasmo por el diálogo y su generosidad para vincular a los estudiantes con otros historiadores brillantes e influyentes para el desarrollo de nuestro oficio profesional. Sus trabajos fueron pioneros y brillantes, tanto para la historia económica cuanto para la iconografía del Perú Colonial y Contemporáneo. Particularmente yo he realizado comentarios críticos a su libro Pintores Populares Andinos, que quisiera se relea nuevamente en esta ocasión, así como sus valiosas y originales reflexiones en torno a la revolución de Túpac Amaru y el significado de su gesta anticolonial de $1780 .{ }^{1}$

Sus trabajos de Historia, publicados en tres tomos por la Casa de la Cultura del Perú, reúnen sus mejores ensayos, así como sus conversaciones con Jorge Basadre, obras ejemplares cuya lectura nos deleita e ilumina intelectual e históricamente.

Yo quisiera agradecer también los comentarios valiosos que hizo a mis libros Ensayos de Nuestra Historia y especialmente Movimientos Campesinos en el Perú, publicado en la Prensa Dominical de los años 80'.

\section{Wilfredo Kapsoli Escudero}

wckapsoli@hotmail.com

Universidad Ricardo Palma

Publicado online: 27/12/2021

1 Publicado originalmente en la revista cusqueña Crítica Andina (1979), (4), 141-147, y reeditado en la revista Apostillas. Revista Crítica de Lecturas Históricas (2017), 4(2), 71-77. https://bit.ly/3mF7j1x 